\title{
Compressed air energy storage facility with water tank for thermal recovery
}

\author{
Iulian Vlăducă ${ }^{1}$, Claudia Borzea $^{1, *}$, Dan Ionescu ${ }^{1}$, Alexandra Țăranu ${ }^{1}$, Răzvan Ciobanu ${ }^{1}$, \\ Vicențiu Ringheanu ${ }^{1}$, and Răzvan Nedelcu ${ }^{2}$ \\ ${ }^{1}$ Romanian Research and Development Institute for Gas Turbines COMOTI, 061126 Bucharest, \\ Romania \\ ${ }^{2}$ TURBONED S.R.L., 210253 Târgu Jiu, Romania
}

\begin{abstract}
The paper presents the prototype of the first Romanian Compressed Air Energy Storage (CAES) installation. The relatively small scale facility consists of a twin-screw compressor, driven by a $110 \mathrm{~kW}$ threephase asynchronous motor, which supplies pressurized air into a $50 \mathrm{~m}^{3}$ reservoir, of 20 bar maximum pressure. The air from the vessel is released into a twin-screw expander, whose shaft spins a $132 \mathrm{~kW}$ electric generator. The demonstrative model makes use of a $5 \mathrm{~m}^{3}$ water tank acting as heat transfer unit, for minimising losses and increasing efficiency and the electric power generated. Air compression and decompression induce energy losses, resulting in a low efficiency, mainly caused by air heating during compression, waste heat being released into the atmosphere. A similar problem is air cooling during decompression, lowering the electric power generated. Thus, using a thermal storage unit plays an essential role in the proper functioning of the facility and in generating maximum electric power. Supervisory control and data acquisition is performed from the automation cabinets. During commissioning tests, a constant stable power of around 50 $\mathrm{kW}$ with an $80 \mathrm{~kW}$ peak was recorded.
\end{abstract}

\section{Introduction}

Electrical energy storage $[1,2]$ is a process in which electrical energy from a power network is converted into a form that can be stored, and then converted back to electrical energy when needed. Such a process produces electricity at times of low demand, when the cost is low, or for the backup of intermittent energy sources such as wind or solar. The energy is stored until a high demand arises or no other energy source is available.

Compressed air energy storage (CAES) is a technique for supplying electric power to the grid for meeting peak load requirements, conventional compressed air energy storage being a practicable technology for electric load levelling. A CAES power generation facility uses electric motor-driven compressors to inject air into a reservoir, later releasing the compressed air to turn turbines and generate electricity into the grid. Even though CAES concept dates back more than four decades ago [3], environmental concerns and technological advances are encouraging their research and development interest to increase worldwide [4-7].

\footnotetext{
* Corresponding author: claudia.borzea@comoti.ro, borzeaclaudia@gmail.com
} 
Compressing and decompressing air introduce energy losses, resulting in a reduced electric-to-electric efficiency. The low efficiency is mainly caused by air heating during compression. This waste heat, which holds a large share of the energy input, is released into the atmosphere. A similar problem is air cooling during decompression, lowering the electricity generated with the risk of water vapours freezing in the air.

The present paper proposes the relatively small-scale ROCAES system, with compressed air storage in high pressure vessels, and with thermal energy recovery by means of a water tank. In the compression and expansion processes occurring in a CAES installation, the heat loss in the compression process, respectively the useful energy loss in the expansion process, are high, in a direct dependency with compressor and expander systems. The screw compressor and screw expander used are machines that work in isothermal cycle, with oil injection for inner rotors lubrication and air temperature control during operation. Depending on the process heat recovery solution chosen, the efficiency of an energy storage station can vary between $41 \%$ and $75 \%$, and a share of more than $65 \%$ of the heat resulted from compression can be recovered in the form of transferred energy [8].

\section{Power plant design with thermal storage}

The CAES system presented consists of a $100 \mathrm{~kW}$ twin-screw compressor that supplies compressed air into a reservoir, and a $132 \mathrm{~kW}$ twin-screw expander. The compressor is driven by a $110 \mathrm{~kW}$ asynchronous three-phase motor. The expander is driven by the compressed air released from the $50 \mathrm{~m}^{3}$ reservoir, spinning a $132 \mathrm{~kW}$ asynchronous three-phase generator. The system's operation has been explained in detail in our previous paper [9]. The block diagram of ROCAES station is presented in Figure 1. Two air storage tanks have been envisaged, currently the installation being commissioned with only one pressurized air tank.

At hourly intervals, when the demand for electricity increases and hence the energy price is higher, the screw expander driving the electric generator starts its operation. The air compression is accompanied by an important energy loss due to the heating of the compressed air in the compression process. The heat of the cooling oil is partially recovered by the $5 \mathrm{~m}^{3}$ water tank, that stores the thermal energy of the oil tray, and transfers it to the oil heating the expander, since air expansion is accompanied by a severe temperature drop.

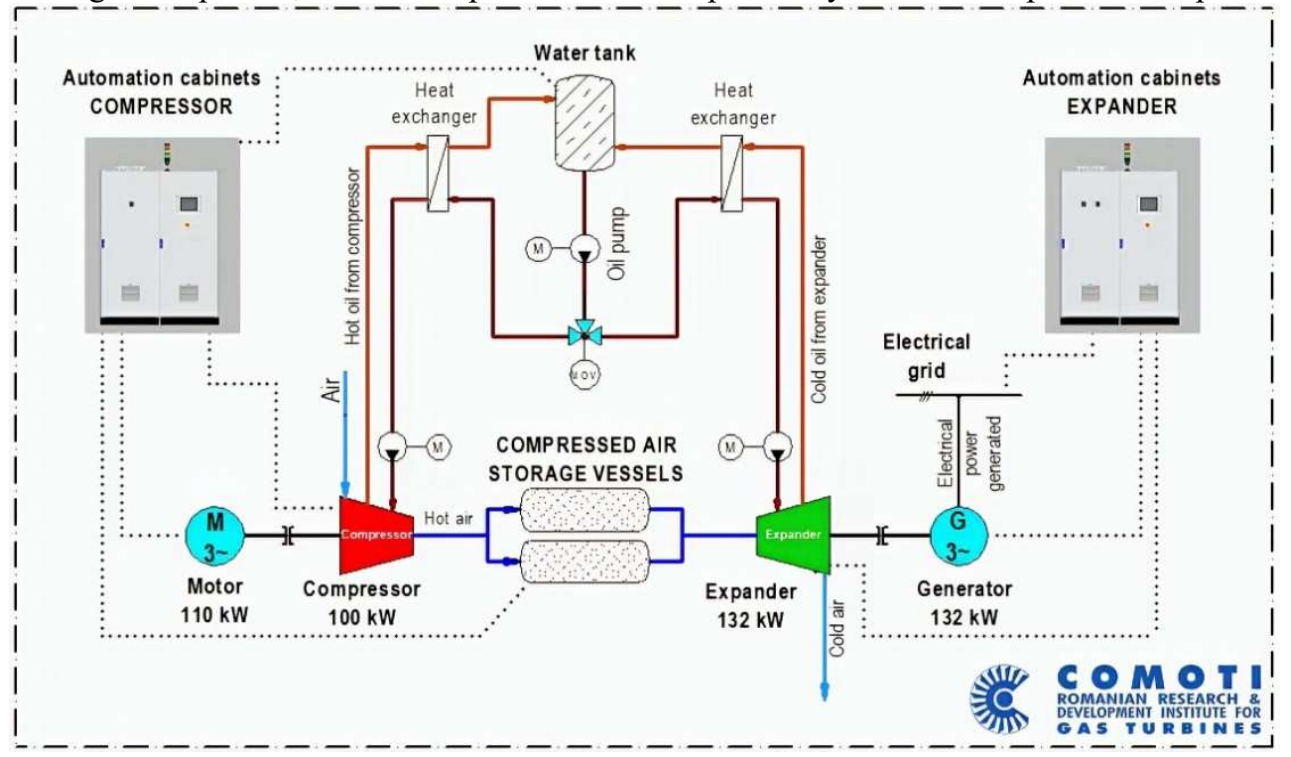

Fig. 1. ROCAES block diagram [10] 
The compressed air is stored in a thermally insulated environment, in order to recover a share of the process heat. In the current configuration, with a $50 \mathrm{~m}^{3}$ air reservoir, it is estimated that the compressor will be able to operate around 4 hours per day, and the expander about 30 minutes, in case of peak electricity demand. During operation, heated oil is necessary to be provided at expander's air inlet, for a better expansion work. The water tank is insulated as well, for reducing heat losses. At a temperature loss gradient of $\sim 1^{\circ} \mathrm{C} / \mathrm{h}$, it is estimated that the temperature in the tank after 20 hours will be $20^{\circ} \mathrm{C}$ lower, considering that the thermal insulation consists of a $50 \mathrm{~mm}$ thick layer of basaltic mineral wool. In Figure 2 below, we present the ROCAES pieces of equipment installed at the commissioning location. The screw compressor, screw expander and the control room are placed inside the production hall, while the compressed air vessel is situated outside. The overall assembly of the ROCAES facility installed in the industrial hall of SC Popeci Heavy Equipment SA (Craiova, Romania) is presented in Figure 2 below.

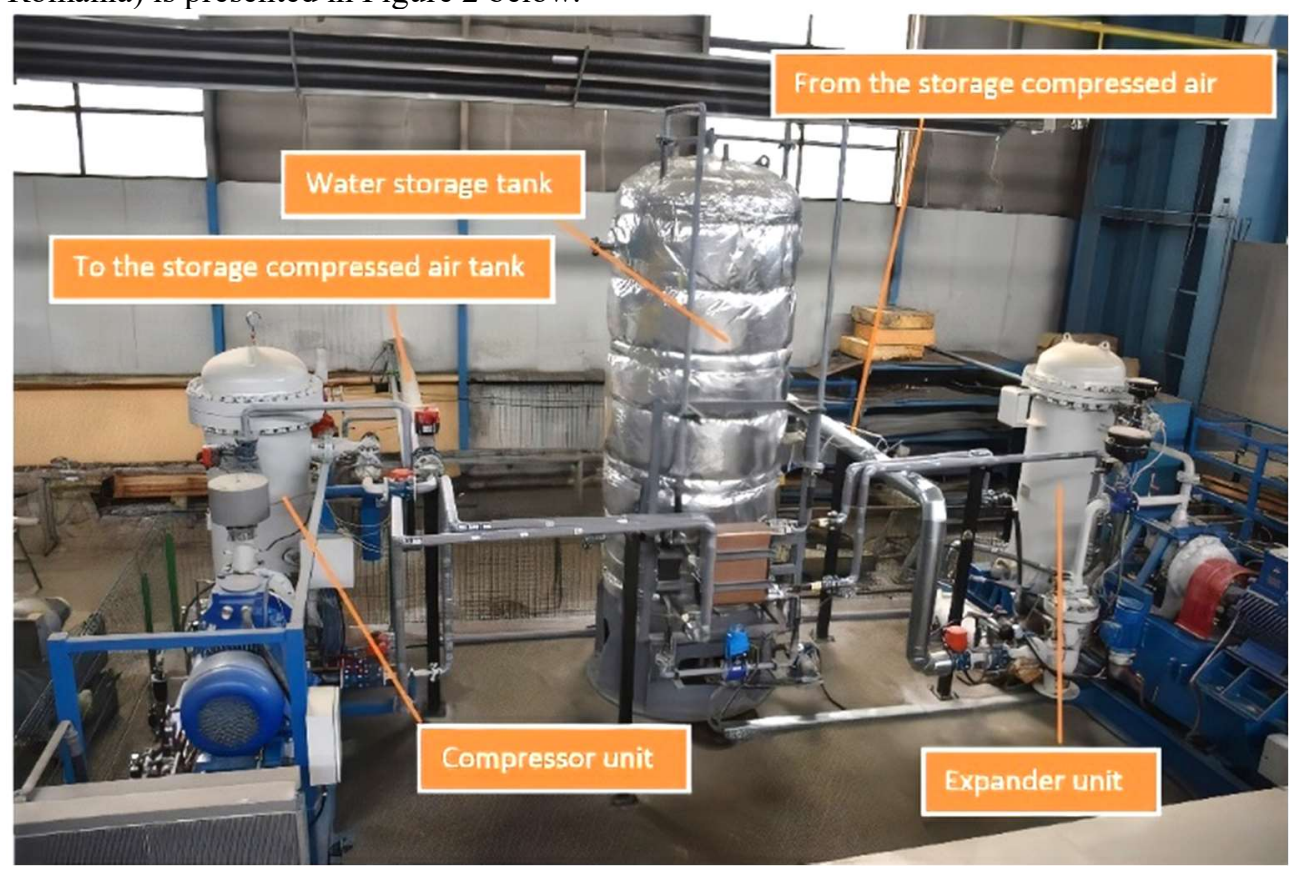

Fig. 2. The ROCAES facility installed at Popeci, Craiova (Romania)

\section{Thermal storage and recovery unit}

\subsection{Water tank design}

Stored thermal energy [11-13] is typically divided into three categories: sensible heat, latent heat, and reaction heat. Sensible heat storage can be recognized in district heating systems or in water heater tanks. Every unit of heat added makes a sensible heat storage medium (water in our case) increase with a certain temperature amount [11]. The installation makes use of a $5 \mathrm{~m}^{3}$ (5000 litres) water tank (Figure 3 left) for oil heat recovery during the cooling and expansion process. Figure 3 right presents the $50 \mathrm{~m}^{3}$ compressed air reservoir. 



Fig. 3. Heat recovery water tank (left) and compressed air reservoir (right)

The cold and hot water in the thermal storage tank are considered to be fully mixed because its volume is relatively low, hence the temperature in the tank is considered to be uniform. This assumption simplifies the analysis because the storage and the load temperature are assumed to be equal [14]. The purpose of the heat recovery module is to store a volume of water (storage medium) resulted from the heated oil resulted from compression, and, at the required time, respectively during the functioning of the expander, to transfer the heat to the oil injected at its inlet. The three-way motor operated valve opens the circuits comprising the heat exchangers. The heat exchange takes place between the hot oil from the compressor and the storage medium represented by the water in the heat recovery module. The water pump mounted on the circuit forces water to flow through the heat exchangers. When the expander is started up, the three-way motor operated valve opens the water circuit that passes through the heat exchanger on the expander circuit. A heat exchange occurs between the storage medium and the oil injected into the expander, a significant part being recovered from the process heat. When the temperature in the separator vessel increases over $60^{\circ} \mathrm{C}$, the PLC (Programmable Logic Controller), through its implemented and programmed software, automatically gives the command of opening the valve to recirculate the oil on the bypass circuit (see the block diagram in Figure 1).

\subsection{Mathematical model}

The computations were realised relying on the following input data: initial water temperature in the vessel $12^{\circ} \mathrm{C}(285.15 \mathrm{~K})$, maximum heated water temperature is $60^{\circ} \mathrm{C}$ $(333.15 \mathrm{~K})$, hence a temperature difference of $\Delta t_{w, \max }=48^{\circ} \mathrm{C}=48 \mathrm{~K}$.

The theoretical evolution of the pressure in the air tank, during compressor operating time, $t_{R}$, was estimated to increase from 6 bar to 17.6 bar in $3837 \mathrm{~s}$. The water quantity rate circulated in $\mathrm{t}_{\mathrm{R}}=1.07$ hours is $m_{v r}=1.303 \mathrm{~kg} / \mathrm{s}$.

The amount of heat rate introduced into the water vessel by the hot oil of the compressor is calculated as:

$$
Q_{u, c}^{t}=m_{v r} \cdot c_{w} \cdot \Delta t_{w, \max }=257.16 \mathrm{~kW}
$$

where: $m_{v r}[\mathrm{~kg} / \mathrm{s}]$ - water quantity rate circulated in the tank volume $\left(m_{v r}=V_{w, \operatorname{tank}} / t_{R}\right.$ where $t_{\mathrm{R}}$ is the compressor operation time, and $V_{w, t a n k}=5 \mathrm{~m}^{3}$ is the volume of the water tank); $c_{w}=4184.4 \mathrm{~J} /(\mathrm{kgK})-$ specific water heat. 
The functioning time for the pressurized air reservoir is important for the heat stored in the water heat recovery tank. Relying on the pressure in the air tank, the functioning of the expander will be analysed in five time intervals extracted from the data acquired during commissioning tests. The energy of the heated water, in the recirculation time $t_{R}=1.07$ hours, is thus calculated as:

$$
W_{a}=Q_{u, c}^{t} \cdot t_{R}=275.16 \mathrm{kWh}
$$

The expander air flow is calculated with the formula below, as the flow was measured with an orifice plate, according to ISO 5167-2 standard.

$$
\dot{\mathrm{M}}_{a}=C \times E \times \varepsilon \times \frac{\pi}{4} \times d^{2} \times\left(2 \Delta P \times \rho_{a}\right)^{\frac{1}{2}}[\mathrm{~kg} / \mathrm{s}]
$$

where: $\dot{\mathrm{M}}_{a}[\mathrm{~kg} / \mathrm{s}]$ - air mass flow; $C$ - discharge coefficient $(=0.65) ; E=1 /\left(1-\beta^{4}\right)^{1 / 2}=1.072$; $\beta=\mathrm{d} / \mathrm{D}=0.754 ; d$ - diaphragm diameter $(=49 \mathrm{~mm}) ; D$ - pipe diameter $(=65 \mathrm{~mm})$; $\varepsilon$ - expansion coefficient $(=0.98) ; \rho_{a}-$ air density on the upstream of the diaphragm; $\Delta P$ - differential pressure on the diaphragm.

The resulting measurement accuracy is about $\pm 1 \%$. From air thermal equation of state, we find the air density:

$$
p \cdot V=R \cdot T \cdot m / M \Rightarrow p=\rho \cdot R \cdot T / M \Rightarrow \rho=p \cdot M /(R \cdot T)
$$

where: $R$ - the universal gas constant $=8314.32 \mathrm{~J} /(\mathrm{kmol} \cdot \mathrm{K}) ; T-$ gas temperature in Kelvin $\left(\mathrm{T}=273+\mathrm{t}\left({ }^{\circ} \mathrm{C}\right)\right.$ ); $M-$ molar mass (for air $\sim 29 \mathrm{~kg} / \mathrm{kmol}$ ). We made the assumption that air is an ideal gas. The computations were realised on five functioning periods, relying on the experimental data, extracted in Table 1.

Table 1. Medium air mass flow and volume flow within the experimental operation periods T1...T5

\begin{tabular}{|c|c|c|c|c|c|}
\hline Period & T1 & T2 & T3 & T4 & T5 \\
\hline Time [s] & 92 & 93 & 152 & 172 & 208 \\
\hline Iterations & 155 & 158 & 259 & 295 & 342 \\
\hline$\overline{\mathbf{M}}_{\mathbf{a}}[\mathbf{k g} / \mathbf{s}]$ & 0.278 & 0.361 & 1.201 & 0.638 & 0.444 \\
\hline
\end{tabular}

The heat rate introduced into the expander oil system is:

$$
Q_{u, \text { exp }}^{t}=\dot{\mathrm{M}}_{\text {oil }} \cdot c_{o i l} \cdot \Delta t_{\text {oil }}[\mathrm{W}]
$$

where: $\dot{\mathrm{M}}_{\text {oil }}[\mathrm{kg} / \mathrm{s}]$ - oil flow mass circulated in the expander; $c_{o i l}=2054 \mathrm{~J} /(\mathrm{kgK})$ - oil specific heat; $\Delta \mathrm{t}_{\mathrm{oil}}[\mathrm{K}]$ - temperature range for oil cooling in the expander. The oil mass flow was calculated using the air heat extracted during expander operation, relying on temperature differences between theoretical cycle without heating through oil injection, and the practical temperature reached during expander operation, with oil injection. The theoretic expansion temperature without air heating is given by the equation:

$$
T_{\text {ev,teor }}=T_{\text {inlet }} \cdot \pi_{t^{\frac{k}{k-1}}}
$$

where: $\pi_{t}$ - expansion ratio; $k$ - isentropic coefficient.

The heat difference is given by the subsequent equation:

$$
\Delta Q_{\text {diff }}=\dot{\mathrm{M}}_{a} \cdot \frac{k}{k-1} \cdot \frac{R}{M} \cdot \frac{k}{k-1} \cdot\left(T_{\text {ev,exp }}-T_{\text {ev,teor }}\right)
$$


where: $T_{e v, \exp }$ value is acquired by the temperature transducer; $T_{e v, t e o r}$ is given by equation (6); $\dot{M}_{a}$ is given by the equation (3); $R$ - the universal gas constant; $M$ - molecular mass of air. The oil flow mass is given by the equation:

$$
\dot{\mathrm{M}}_{\text {oil }}=\frac{\Delta Q_{\text {diff }} \cdot(k-1) \cdot M}{k \cdot R \cdot\left(T_{\text {oil }, \exp }-T_{\text {ev, exp }}\right)}
$$

\section{Automation system and commissioning tests}

The purpose of the automated SCADA (Supervisory Control and Data Acquisition) system, represented by the independent sets of drives and automation cabinets for compressor and expander automation respectively, is to control and monitor the operation parameters of thermal, mechanical and electrical processes, to regulate and keep these ones within certain operation limits, in order to ensure maximum safety conditions. On compressor and expander skids, transducers are mounted for monitoring the important parameters of the installation. The information from the transducers is transmitted to the two separate PLCs located in the automation cabinets, for the independent operation of expander and compressor units.

After filling the compressed air reservoir with the compressor operating for about 4 hours, reaching a pressure of about 16 bar, the compressor was shut down. Then, the expander air inlet valve was opened, and the asynchronous three-phase machine was started in motor regime, with a softstarter, until reaching no load speed ( 1470 rpm). Compressed air from the storage tank was released into the expander by opening the reservoir valve towards expander. The pressurized air released turns the expander, whose shaft spins the shaft of the electric machine above the synchronous speed of $1470 \mathrm{rpm}$, this one entering automatically in generator regime and injecting electric power into the grid.

The minimum pressure condition set at expander inlet is 2 bar. If not meeting this condition, the expander goes through an automatic shutdown sequence. The condition was set considering the minimum pressure in the air reservoir dropping down to 4-5 bar, considering the pressure losses until air reaching expander's inlet. In Figure 4 are presented the control panels interfacing the two PLCs, during compressor and expander operation tests.
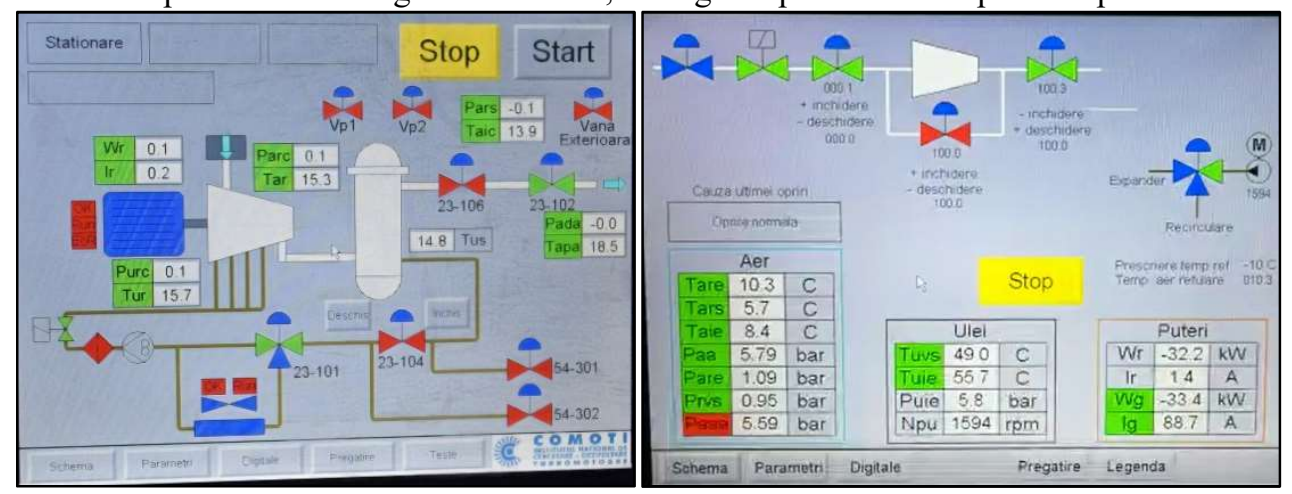

Fig. 4. Compressor (left) and expander (right) control panels showing real-time parameters

In the subsequent figure, the generated power at the first experimental start-up is presented, for commissioning period $\mathrm{T} 1$. The positive power shows that the asynchronous electric machine is launched as motor, absorbing power from the grid. Then, as the expander inlet valve gradually opens to suction air from the reservoir, the electric machine is spun over its synchronous speed as generator. It has a normal instantaneous spike of almost $40 \mathrm{~kW}$ generated power when reaching synchronous speed, and then it begins to stabilize in generator regime, injecting almost $80 \mathrm{~kW}$ maximum electric power. 


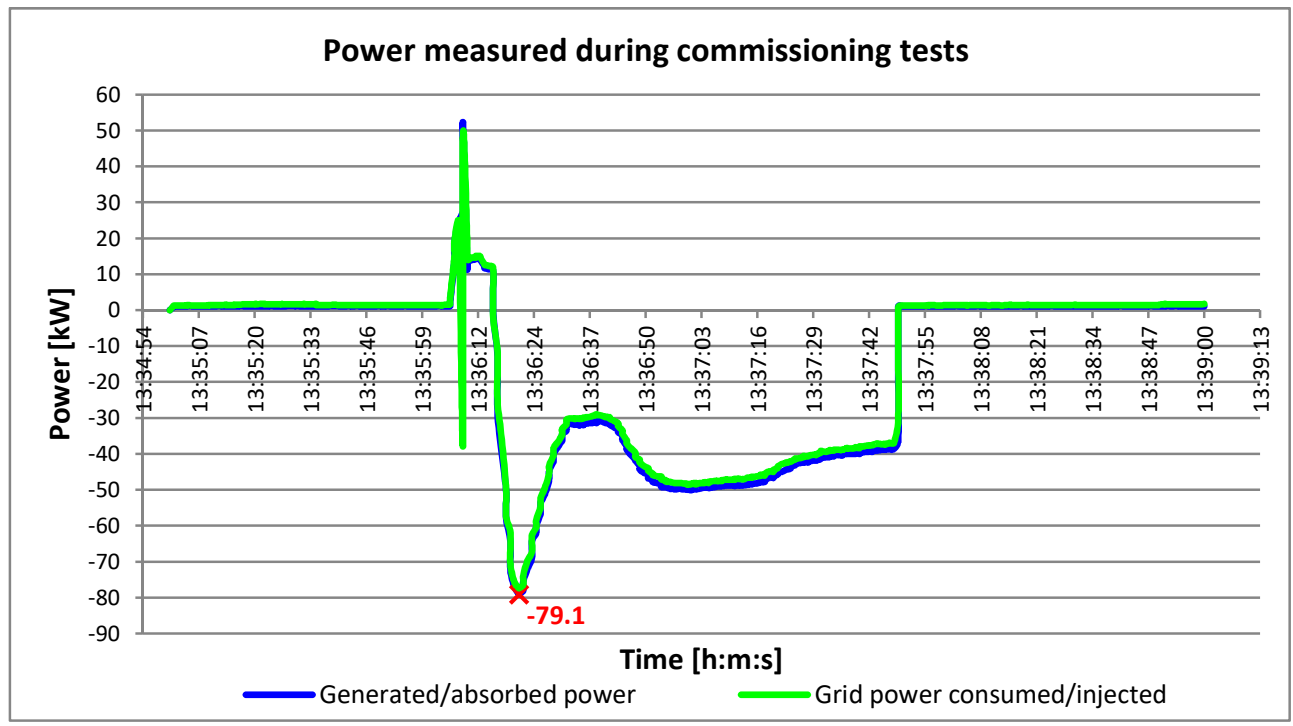

Fig. 5. Power plot relying on acquired data during commissioning test for period $\mathrm{T} 1$

The two power curves in Figure 5 are very close, but the injected power into the grid is slightly lower because electric consumers in the electric cabinets also need to be supplied with the power produced. The other T2...T5 periods have similar power graphs.

\section{Experimental and theoretical results}

Both the maximum power and the stabilization power (Figure 5 above) were significantly higher than the ones obtained during bench tests without thermal recovery tank, even with preheating oil with a heating resistance $[9,10]$. In the tables below are given the parameters ranges (minimum and maximum values), measured during commissioning tests.

Table 2. The parameters ranges acquired during operation periods $\mathrm{T} 1 \ldots \mathrm{T} 5$

\begin{tabular}{|c|c|c|c|c|c|}
\hline & $\mathrm{T} 1=92 \mathrm{~s}$ & $T 2=93 \mathrm{~s}$ & $T 3=152 \mathrm{~s}$ & $\mathrm{~T} 4=172 \mathrm{~s}$ & $T 5=208 s$ \\
\hline $\begin{array}{l}\text { Electric grid } \\
\text { power }[\mathrm{kW}]\end{array}$ & $56.7 \ldots 50.4$ & $77.4 \ldots 30.2$ & $65 \ldots 6$ & $15.7 \ldots 14.1$ & $39.1 \ldots 18.8$ \\
\hline $\begin{array}{l}\text { Expander inlet oil } \\
\text { temperature }\left[{ }^{\circ} \mathbf{C}\right]\end{array}$ & $33.5 \ldots 42.3$ & $65.6 \ldots 60$ & $48.4 \ldots 52$ & $44.8 \ldots .51 .4$ & $50.6 \ldots 55.8$ \\
\hline $\begin{array}{l}\text { Expander outlet oil } \\
\text { temperature }\left[{ }^{\circ} \mathbf{C}\right]\end{array}$ & $15.7 \ldots 15.2$ & $12.9 \ldots-20$ & $9.6 \ldots-7.6$ & $-2 \ldots-16.8$ & $15.2 \ldots-18.3$ \\
\hline $\begin{array}{c}\text { Air temperature at } \\
\text { separator outlet }\left[{ }^{\circ} \mathrm{C}\right]\end{array}$ & $14.2 \ldots 11.7$ & $13.7 \ldots 9.3$ & $9.6 \ldots 8.9$ & $16 \ldots 9.7$ & $12.3 \ldots 7.8$ \\
\hline $\begin{array}{l}\text { Expander inlet air } \\
\text { temperature }\left[{ }^{\circ} \mathrm{C}\right]\end{array}$ & $14.7 \ldots 11.7$ & $16.1 \ldots 12.6$ & $14 \ldots 9.8$ & $13.9 \ldots 8.1$ & $13.1 \ldots 6.2$ \\
\hline $\begin{array}{l}\text { Expander outlet } \\
\text { pressure [bar] }\end{array}$ & $2.9 \ldots 2.3$ & $2.6 \ldots 3.6$ & $1.8 \ldots 3.2$ & $4.1 \ldots 2.8$ & $1.9 \ldots 1.3$ \\
\hline $\begin{array}{l}\text { Air pressure before } \\
\text { flowmeter [bar] }\end{array}$ & $11.7 \ldots 9.6$ & $12.6 \ldots 10.2$ & $10.6 \ldots 8.8$ & $11.1 \ldots 8.2$ & $7.7 \ldots .5 .1$ \\
\hline $\begin{array}{l}\text { Expander inlet } \\
\text { pressure [bar] }\end{array}$ & $10.3 \ldots 9$ & $11 \ldots 9.2$ & $8.9 \ldots 7.7$ & $9.6 \ldots 7.7$ & $7.3 \ldots 4.7$ \\
\hline
\end{tabular}


In Table 2 we selected the minimum and maximum values from a total of 24 values used for iterations in PTC Mathcad software, where the computations were performed. The power of the expander is given by the following relation:

$$
P_{\text {exp }, \text { teor }}=\dot{\mathrm{M}}_{a} \cdot \frac{k}{k-1} \cdot \frac{R}{M} \cdot T_{\text {asp }} \cdot \frac{\left[\left(\pi_{t}\right)^{\frac{k-1}{k}}-1\right]}{\eta_{\text {correction }}} / 1000 \mathrm{~kW}
$$

where $\pi_{\mathrm{t}}$ is the expansion coefficient, having the expression:

$$
\pi_{t}=\frac{p_{\text {ev }, \exp }+1}{p_{\text {inlet }, \exp }+1}
$$

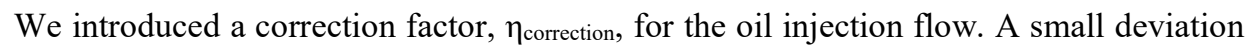
from the air flow rate $\dot{\mathrm{M}}_{a}$ induces a significant error in the difference of heat exchanged with the oil $\Delta Q_{\text {diff }}$ calculated in equation (7). The air mass flow $\dot{\mathrm{M}}_{a}$ depends on the Reynolds number air flow measured with the orifice plate in the diaphragm. An adjustment in Reynolds number gives the $\eta_{\text {correction }}$ factor used to calculate more accurately the overall efficiency. In Table 3 are given the maximum values of the oil flow rate $\dot{\mathrm{M}}_{\text {oil }}(1 / \mathrm{min})$ at a density $\rho_{\text {oil }}$ of 905 $\mathrm{kg} / \mathrm{m}^{3}$ for ISO VG 68 oil type used, the injection oil heat rate $Q_{\text {oil_injection }}$ and the theoretical calculated power of the expander $P_{\text {exp,teor }}$, as well as the expansion coefficient $\pi_{t}$.

Table 3. The medium injected oil heat and expansion coefficient $\pi_{t}$ vs. theoretical expander power

\begin{tabular}{|c|c|c|c|c|c|}
\hline Period & T1 & T2 & T3 & T4 & T5 \\
\hline seconds & 92 & 93 & 152 & 172 & 208 \\
\hline$\dot{\mathrm{M}}_{\text {oul }}[\mathbf{k g} / \boldsymbol{s}]$ & 0.207 & 0.149 & 0.632 & 0.175 & 0.241 \\
\hline$\overline{\boldsymbol{Q}_{\text {oul_injection }}}[\mathbf{k W}]$ & 15.9 & 18.9 & 60.8 & 18.9 & 24.7 \\
\hline$\overline{\pi_{\boldsymbol{t}}}[\mathbf{N D}]$ & 0.335 & 0.391 & 0.456 & 0.436 & 0.384 \\
\hline$\overline{P_{\text {exp,teor }}}[\mathbf{k W}]$ & 61.1 & 73.1 & 79.0 & 36.6 & 37.9 \\
\hline
\end{tabular}

It is observed from Table 3 that at a maximum $\pi_{\mathrm{t}}$ and a maximum heat oil rate injected Qoilinjection, we obtain the maximum theoretical power. The medium heat rate necessary for expander heating during T1..T5 periods is estimated as $Q_{\text {oil } \_ \text {injection,medium }}=27.84 \mathrm{~kW}$. The efficiency was determined iteratively, for a positive and linear increasing of the $\Delta Q_{\text {diff }}$ with the oil mass flow $\dot{\mathrm{M}}_{\text {oil }}$, as $\eta_{\text {medium }}$ being the medium ratio between theoretical power $\mathrm{P}_{\text {teor }}$ and experimental power $\mathrm{P}_{\exp }$ in 24 iterations, and:

$$
\eta_{\text {global }}=\eta_{\text {medium }} \cdot \eta_{\text {correction }}
$$

In Table 4 are given the efficiencies calculated for all experimental operation ranges.

Table 4. The efficiencies calculated for T1...T5 periods

\begin{tabular}{|c|c|c|c|c|c|}
\hline Period & T1 & T2 & T3 & T4 & T5 \\
\hline seconds & 92 & 93 & 152 & 172 & 208 \\
\hline $\boldsymbol{\eta}_{\text {correction }}$ & 0.35 & 0.35 & 1 & 0.8 & 0.8 \\
\hline $\boldsymbol{\eta}_{\text {medium }}$ & 83.2 & 79.1 & 31.0 & 53.7 & 64.9 \\
\hline $\boldsymbol{\eta}_{\text {global }}$ & 29.1 & 27.7 & 31.0 & 43.0 & 51.9 \\
\hline
\end{tabular}

The expander oil was heated from $-10^{\circ} \mathrm{C}$ to $56^{\circ} \mathrm{C}$ with the water stored in the storage water tank. The oil used for recirculation was drawn from the separator vessel of the expander, where the temperature was $\sim 12^{\circ} \mathrm{C}$. If we consider that the energy of the oil from 
$-10^{\circ} \mathrm{C}$ to $12^{\circ} \mathrm{C}$ was lost in the process, we obtain the values in Table 5. The medium heat rate lost in the process was $Q_{\text {loss }} \cong 8.6 \mathrm{~kW}$.

Table 5. Heat lost during T1...T5 commissioning periods

\begin{tabular}{|c|c|c|c|c|c|}
\hline Period & T1 & T2 & T3 & T4 & T5 \\
\hline seconds & 92 & 93 & 152 & 172 & 208 \\
\hline $\boldsymbol{Q}_{\text {oil_injection }}[\mathbf{k W}]$ (lost) & 6.0 & 5.98 & 14.2 & 10.98 & 5.85 \\
\hline
\end{tabular}

The water pump circulates the water in the expander heat exchanger with the same flow as the compressor heat exchanger, that is $m_{v r}=1.303 \mathrm{~kg} / \mathrm{s}$.

The energy that can be produced for a functioning with $1^{\circ} \mathrm{C}$ decrease in the water temperature, with the rate of $m_{v r}$, is:

$$
Q_{u, c}^{t}=\dot{M}_{v r} \cdot c_{w} \cdot \Delta t_{w, \max }=5452.2 \mathrm{~W}
$$

In order to achieve the medium heat rate Q Qoil_injection,medium of $27.84 \mathrm{~kW}$ needed for the expander, the water circulation rate should be:

$$
\dot{M}_{v r}=m_{v r} \cdot \frac{Q_{\text {oil_injection,medium }}}{Q_{u, c}^{t}}=6.65 \mathrm{~kg} / \mathrm{s}
$$

The amount of energy extracted from the 5000 litres of water, with a water mass flow of $6.65 \mathrm{~kg} / \mathrm{s}(399.2 \mathrm{l} / \mathrm{min})$, requires a total time of functioning $t_{R, t o t a l}$ of $\sim 12.5$ minutes for $1^{\circ} \mathrm{C}$ of water temperature decrease This time should be enough for the expander operating at the recorded parameters, for a total functioning time in generator regime, that was:

$$
t_{R, \exp }=\sum_{i=1}^{5} T_{i}=T 1+T 2+\ldots+T 5=717 \mathrm{~s}
$$

The total energy required for cooling the expander, during the total operation time of about $0.2 \mathrm{~h}$ (12 minutes), is:

$$
W_{\text {total }}=\left(Q_{\text {oil,injection,medium }}+Q_{\text {loss,medium }}\right) \cdot t_{R, \exp }=7.3 \mathrm{kWh}
$$

\section{Conclusions}

The ROCAES power facility was installed and commissioned at the industrial hall of Popeci Heavy Equipment plant in Craiova, Romania. It comprises a screw electro-compressor, driven by a $110 \mathrm{~kW}$ motor and a screw expander driving a $132 \mathrm{~kW}$ electric generator. The compressed air is stored in a $50 \mathrm{~m}^{3}$ reservoir, of 20 bar maximum pressure. The demonstrative model makes use of a $5 \mathrm{~m}^{3}$ water tank for minimising thermal energy losses, increasing the efficiency and generated power.

Air compression and decompression processes are accompanied by energy losses due to air heating during compression, releasing waste heat into the atmosphere, and air cooling during decompression, lowering the electric power generated. This results in a low efficiency, hence using a thermal storage tank has an important part in the operation of the installation and in generating higher electric power.

A stabilized power of around $50 \mathrm{~kW}$ with a maximum of $80 \mathrm{~kW}$ was obtained. Both the peak power and the stabilization power recorded were found to be significantly higher than the ones obtained during in-house bench tests without the water tank, even if oil preheating was ensured.

For a reliable CAES energetic process, the aimed performances are of minimum 30 minutes of continuous operation at around $80 \mathrm{~kW}$, considering $80 \%$ generator efficiency. A water temperature of $60^{\circ} \mathrm{C}$ requires higher oil and water mass flow through the heat 
exchangers, thus increasing the electrical energy consumed. For more power, a higher capacity of the air storage reservoir(s) is required, able to attain a higher pressure. Introducing an additional compressor stage as in [7], of higher pressure, would also increase the overall performances.

Further researches will consider increasing the stored capacity of compressed air, using two or more reservoirs. As well, an efficient solution for increasing the temperature of the stored water to a maximum of $90^{\circ} \mathrm{C}$ will be sought, and in case of not having enough energy for the expansion process, a parallel oil heating device will be ensured.

The research work presented herein was funded by Competitiveness Operational Program 2014-2020, Priority Axis 1 - Research, Technological Development and Innovation in Support of Economic Competitiveness and Business Development, Action 1.2.3, Partnerships for Knowledge Transfer, contract POC 79 / 08.09.2016, carried out with the support of Romanian Ministry of European Funds.

\section{References}

1. H. Chen, X. Zhang, J. Liu, T. Chunqing, Compressed Air Energy Storage, in Energy Storage - Technologies and Applications, 101-112 (IntechOpen, 2013), DOI:10.5772/52221.

2. S. D. Garvey, A. Pimm, Compressed Air Energy Storage, in Storing Energy, 87-111 (Elsevier, 2016). DOI:10.1016/B978-0-12-803440-8.00005-1.

3. R. Allen, T. Doherty, L. Kannberg, Summary of selected compressed air energy storage studies, (Pacific Northwest National Laboratory (U.S.), 1985), https://www.osti.gov/servlets/purl/5872515.

4. C. Guo, Y. Xu, X. Zhang, H. Guo, X. Zhou, C. Liu, W. Qin, W. Li, B. Dou, H. Chen, Energy 135, 876-888 (2017), DOI:10.1016/j.energy.2017.06.145.

5. G. Venkataramani, V. Ramalingam, K. Viswanathan, Sci. Rep., 8(1), 9981 (2018), DOI:10.1038/s41598-018-28025-5.

6. Chen, T. Zheng, S. Mei, X. Xue, B. Liu, Q. Lu, J, Modern Power Syst. Clean Ener. 4(4) 529-541 (2016), DOI:10.1007/s40565-016-0240-5.

7. G. Dib, P. Haberschill, R. Rullière, Q. Perroit, S. Davies, R. Revellin, Appl. Ener. 260, 114248 (2020). DOI: 10.1016/j.apenergy.2019.114248.

8. M. Broniszewski, S. Werle, E3S Web of Conf. 70, 03001 (2018), DOI:10.1051/e3sconf/20187003001.

9. C. Borzea, I. Vlăducă, D. Ionescu, V. Petrescu, F. Niculescu, C. Nechifor, G. Vătășelu, M. Hanek, E3S Web of Conf 112, 02010 (2019), DOI:10.1051/e3sconf/201911202010.

10. C. Borzea, A. Săvescu, C. Hărăguță, A. Găzdac, R. Nedelcu, Elect. Mach., Mater. and Drives - Pres. and Trends), 1(1), 1-12 (2020), DOI:10.36801/apme.2019.1.2.

11. I. Dincer, M. Ezan, Thermal Energy Storage Applications, in Heat Storage: A Unique Solution for Energy Systems, 85-135 (Springer, 2018). DOI:10.1007/978-3-319-918938 .4.

12. O. Burheim, Thermal Energy Storage, in Engineering Energy Storage, 47-61 (Elsevier, 2017). DOI:10.1016/b978-0-12-814100-7.00004-3.

13. P. Li, C. Chan, Thermal Energy Storage Materials, in Thermal Energy Storage Analyses and Designs, 21-63 (Elsevier, 2017). DOI:10.1016/b978-0-12-805344-7.00003-1.

14. M. Sameti, A. Kasaeian, S. Mohammadi, N. Sharifi, Sust. Ener., 2(2), $52-56$ (2014). DOI:10.12691/rse-2-2-3. 